\title{
Towards the profiling of the atmospheric boundary layer at European scale-introducing the COST Action PROBE
}

\author{
Domenico Cimini ${ }^{1,2}$ (D) Martial Haeffelin ${ }^{3} \cdot$ Simone Kotthaus $^{3} \cdot$ Ulrich Löhnert $^{4}$.

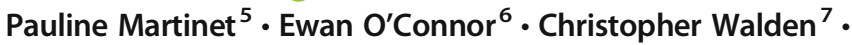 \\ Martine Collaud Coen $^{8}$ (D) . Jana Preissler ${ }^{9,10}$
}

Received: 15 November 2019 / Accepted: 13 January 2020 / Published online: 26 February 2020

(C) The Author(s) 2020

\begin{abstract}
The atmospheric boundary layer (ABL) is the layer closest to the Earth's surface within which most human activities take place. The vertical profile of atmospheric thermodynamic parameters in the ABL impact weather, air quality and climate. However, surface sensor networks and satellite observations do not provide sufficient information on the high temporal variability and strong vertical gradients that occur in the ABL. Thus, the ABL represents an important but rather under-sampled part of the atmosphere. This observational gap currently hampers progress in numerical weather prediction, air quality forecasting and climate assessment. Due to recent technological and methodological advances, ground-based remote sensing instruments are now able to provide highquality profiles of ABL parameters such as temperature, humidity, wind, aerosol and cloud properties. However, even though state-of-the-art ABL profilers are deployed at numerous sites in Europe, efficient science and technology networking and coordination is still required to exploit this rich dataset effectively. The current lack of data and procedure harmonization often diminishes the potential societal benefits of the existing ABL profiling data. This paper introduces PROBE, a new initiative funded by the European Cooperation in Science and Technology (COST), that aims to broaden the bridge between a wide range of user needs and the science and technology expertise residing in industry and academia, while strengthening and harmonizing methods and procedures to yield higher quality ABL observational data. Here, the challenges, objectives and implementation plan for PROBE are described, highlighting some preliminary results that will be further developed into operational applications during the 4-year duration (2019-2023) of this collaborative project.
\end{abstract}

Keywords COST Action PROBE · Atmospheric boundary layer · Vertical profiling

Domenico Cimini

domenico.cimini@imaa.cnr.it

Extended author information available on the last page of the article 


\section{Introduction}

The atmospheric boundary layer (ABL) is the layer of the atmosphere closest to the Earth's surface, within which most human activities take place. The ABL is directly influenced by surface-atmosphere exchanges of heat, moisture and other constituents, with impacts from the biosphere and anthropogenic activities playing a role. In return, human activities are influenced by the ABL characteristics of wind, temperature, humidity, fog, clouds, precipitation and air quality (Friehe 1987; Stull 1988; Garratt 1994).

Disproportionately to its relevance, the observational knowledge of the ABL is scarce. Meteorological surface sensor networks only gather standard atmospheric variables near the ground while satellite observations of the ABL are limited by strong attenuation of their signal in clouds, their lack of high vertical resolution in the ABL and the large uncertainty of retrieval algorithms close to the surface due to limited knowledge of variable surface characteristics (such as albedo). The only global coordinated measurement network providing profile observations at a high vertical resolution within the ABL are radiosondes. While radiosondes provide essential measurements for atmospheric vertical profiling, they are spatially sparse and their low temporal frequency is not nearly appropriate for capturing the diurnal variation in the ABL. The drawbacks of current operational monitoring systems may be reduced by increasing the use of existing groundbased profiling technology. However, compared with the well-established programs for satellite, surface and radiosonde measurement networks, ABL profiling efforts still lag behind in terms of coordination and international standards.

Atmospheric profiling has the ability to capture vertical variations in atmospheric conditions that are key for characterizing ABL dynamics and structure at a given location and to better understand atmospheric exchange processes. With high-resolution atmospheric models emerging, 4-D observations of multiple variables capturing the diurnal evolution of ABL dynamics are needed for model evaluation, development and data assimilation (NRC 2009; Barlow et al. 2017). To cater to the needs of the modelling community, both suitable products of high quality, and tools for data quality control, processing and assimilation, are required.

Several additional fields of applications could benefit from atmospheric profiling measurements, in the domains of both scientific research and societal activities. Air quality authorities in charge of monitoring and forecast could benefit from more precise information on the vertical distribution of aerosols, as well as dynamical profiles to better account for atmospheric mixing. Cities and local governments concerned with mitigation and adaptation to climate change could also benefit from more precise data regarding temperature humidity and wind profiles and their spatial heterogeneities in dense urban environment, with a particular concern to severe weather events. The construction business is in high demand for vertical profiles of wind in particular for urban environments. Airport activities that are highly weather dependent could benefit from more precise knowledge of turbulence and hydrometeor (e.g. fog/stratus) profiles. This applies to railway and road traffic as well. The renewable energy sector must have access to precise datasets to quantify wind and solar resources and their variability. This includes wind and turbulence profiles for wind energy and aerosol and cloud profiles for solar energy, especially for plants based on concentrated solar power. The insurance business is also a domain that is highly interested in weather and climate data, specifically in the atmospheric boundary layer where human activities take place.

The importance of ABL profiling has hence been widely recognized for several applications (Seibert et al. 2000; Emeis et al. 2008; Hardesty et al. 2012; Barlow 2014; Cimini et al. 2014; 
Dang et al. 2019) that can be grouped into five critical areas of societal needs (NRC 2009; Hardesty et al. 2012): energy security, public health and safety, transportation, water resources and food production. In particular, three high-priority emerging weather research needs have been identified: very-high-impact weather, urban meteorology and renewable energy development. Reaching out to new potential user communities that could benefit from continuous ABL profiling by dense monitoring networks is hence an important objective to be pursued.

To determine spatio-temporal ABL variations, ground-based profiling networks need to provide high-quality long-term measurements at high vertical and horizontal resolution. Atmospheric variables of interest include vertical profiles of aerosol and cloud characteristics, wind, turbulence, air temperature and humidity. ABL profiling measurements are currently performed at a large number of sites in Europe. However, profiling systems are deployed and operated in response to a variety of interests by the different state and regional governments, research institutes, universities and the private sector. As a result, a diverse range of technologies, hardware settings and processing procedures are being used, lacking a common framework at the European (or even global) level.

Thus, despite the indications of a high impact per cost-effectiveness of ground-based ABL profiling networks (Eyre and Reid 2014), the current situation hampers the effective use of extensive existing data, which thus remain underexploited.

State-of-the-art ground-based remote sensing instruments deployed worldwide for ABL profiling include the following:

- Wind profilers

- Radar wind profiler (RWP)

- Doppler wind lidar (DWL)

- Temperature profilers

- microwave radiometer (MWR)

- Raman lidar (RL)

- Humidity profilers

- MWR

- RL

- Differential absorption lidars (DIAL)

- Aerosol profilers

- elastic lidars

- automatic lidar ceilometer (ALC)

- RL

- Cloud profilers

- ALC

- Cloud radar (CR)

In view of global economic constraints, which make massive deployment of new instrumentation unlikely, coordination efforts shall build on existing observing resources, fostering innovative 
research aiming at network optimization and enhanced synergy between different observing strategies.

Recently, a number of surveys have shown that more than 700 ALC, 15 RL, 20 DWL, 30 RWP, 30 MWR and 15 CR are currently operated in Europe, typically by operational agencies (e.g. national meteorological services) or research institutions. To exploit these valuable observations most cost-effectively, innovative research should help identifying and closing observational gaps as well as assessing how higher order products can be derived based on synergy of different observing techniques. However, the inclusion of these vast resources in a structured and coordinated monitoring system is a complex process, involving several initiatives. Among these, the European meteorological services network (EUMETNET) Composite Observing System (EUCOS) is responsible for the development of the observing system in Europe to serve the needs of regional numerical weather prediction (NWP). EUCOS is currently running the E-PROFILE programme (www.eumetnet.eu/e-profile) to address the networking of various profiling instruments.

Similarly, the European Research Infrastructure ACTRIS will design and implement a longterm research infrastructure to support scientific research observational needs related to aerosols, clouds and trace gases (www.actris.eu) based on RL, CR, ALC and MWR among other instruments. The above initiatives have benefited from research cooperation within former European Cooperation in Science and Technology (COST) Actions. Established in 1971, COST (www.cost.eu) is the oldest and widest European intergovernmental network for cooperation in research, presently counting 38 European countries as well as cooperating and partner members. The COST mission is to provide networking opportunities for researchers and innovators in order to strengthen Europe's capacity to address scientific, technological and societal challenges. The mission is implemented by funding bottom-up, excellence-driven, open and inclusive networks for peaceful purposes in all areas of science and technology. COST funding is exclusively dedicated to collaboration activities, covering basic and applied research and addressing issues of societal importance or pre-normative nature. COST represents a global, open and inclusive networking mechanism, currently engaging about 45,000 researchers and innovators.

In the field of ABL profiling, research coordination within former COST Actions was instrumental to improving data quality and derive value-added products for climate and research applications, providing the expertise and the networking opportunities needed to develop recommendations and new methods, algorithms, firmware and software. Among others, the following COST Actions have significantly contributed to the development and application of ABL profiling systems within the European observation network.

- COST Action 76 (1995-1999), "Development of VHF/UHF Windprofilers and Vertical Sounders for Use in European Observing Systems", set the basis for the development of radar wind profilers and their networking for the integration in the European observing system (Nash et al. 2003).

- COST Action 712 (1996-2000), "Application of microwave radiometry to atmospheric research and monitoring", set the basis for the development of radiative transfer models and code for microwave radiometry (Mätzler 2000).

- COST Action 715 (1999-2003), "Meteorology applied to Urban Air Pollution Problems", produced an inventory of urban meteorological sites (Fisher et al. 2005).

- COST Action 720 (2000-2006), "Integrated Ground-based Remote-Sensing Stations for Atmospheric Profiling", reviewed the progress within each ABL profiling technique and 
towards instrument synergy for the derivation of additional products. It also set the basis for a EUMETNET observatory-type network, it introduced concepts for cost-effective combination of ABL profiling systems and it promoted field campaigns to evaluate NWP model output (Engelbart et al. 2009).

- COST Action ES0702 (2008-2012), "European Ground-based observations of essential variables for CLImate and operational METeorology" (EG-CLIMET), advanced the exploitation of existing ground-based profiling stations for climate and meteorology applications. EG-CLIMET addressed four profiling sensor types (ALC, DWL, RWP, MWR) that, at relatively low cost, could contribute significantly to NWP. EG-CLIMET performed a survey of instruments already deployed in Europe, demonstrating their performances in various conditions. EG-CLIMET also compared the ground-based profiling products with the NWP model predictions. The results were presented to EUCOS with the recommendation to operate these sensors in a monitoring network to provide real-time data. Thus, EG-CLIMET made a substantial contribution in triggering and defining the EPROFILE program established by the EUMETNET Observations Program Manager (Haeffelin et al. 2012; Illingworth et al. 2013; Illingworth et al. 2015).

- COST Action ES1303 (2013-2017), “Towards Operational Ground-Based Profiling with Ceilometers, Doppler Lidars and Microwave Radiometers for Improving Weather Forecasts" (TOPROF), specifically addressed the remaining issues with the three relatively newer sensor types (ALC, DWL, MWR). TOPROF focused on the setup of common calibration techniques and operating procedures, developing retrieval algorithms and uncertainty characteristics, and building homogeneous and reliable data quality control for the three classes of instruments (Illingworth et al. 2019 and references therein). TOPROF provided standardized software and calibration procedures that have been implemented in the E-PROFILE processing. E-PROFILE currently distributes in realtime profiles of aerosol and cloud backscatter from a network of 303 ALCs from 22 countries (as of October 2019) to European weather forecast centres. TOPROF finally proposed the extension of E-PROFILE to DWL and MWR, which are now considered in E-PROFILE 2nd phase (2019-2023) in form of the preparation of two business cases that shall demonstrate respective benefits.

To maintain excellence established in the framework of previous COST actions, continued quality control and interaction between manufacturers, research community and stakeholders are required. In addition, capabilities and potential benefits of new technologies (such as DWL and DIAL) that have reached the market in recent years need to be quantified. These goals will be addressed by the new COST Action (CA18235) "PROfiling the atmospheric Boundary layer at European scale" (PROBE), proposed in 2018 and selected for funding for the period 2019-2023. Here, we describe current challenges and outline PROBE objectives, highlighting the innovation potential illustrated by a few early results.

\section{Challenges and objectives}

The ABL observational gap calls for improved and systematic profiling of the lower atmosphere, i.e. the lowest $2-3 \mathrm{~km}$ above ground where the vertical structure is driven by surfaceatmosphere exchange processes in response to local orography, land cover and biological and human activities in addition to the synoptic scale weather conditions. However, due to the 
complexity of high-technology ABL profiling instruments and the large variety of end-users, their operators often lack expertise and common training regarding the most appropriate measurement setup and best practice in data processing that allow for full exploitation of such data. Optimized operation of ABL profiling sensors includes appropriate measurement configurations, consistent maintenance activities, absolute calibrations and post-processing, data format harmonization and quality control. This poses a clear need for operational guidelines and harmonized processing procedures to ensure maximum quality and consistency throughout the sensor networks for use in a wide range of applications, adding value to the network data products and the deployment investment. Maintaining and even expanding the pool of high-level expertise can only be achieved by a consortium of research scientists, instrument manufacturers, operational agencies and end-users.

Increased harmonization of existing ABL profiling observations and data processing will result in improved quality control, more complete and uniform metadata, and easier data access. Coordination of ABL profiling at the European scale is thus pivotal to pave the road towards new and improved weather and climate services (e.g. NWP, high-impact weather warnings, air quality and renewable energy forecasts, site climatology). An overarching strategy is required to integrate the current and future aims and efforts at European level, vastly augmenting socioeconomic benefits that can be obtained. Following the Network-of-Networks (NRC 2009) and System-of-Systems (Thorne et al. 2017) tiered approaches, scientific and technological coordination will make ABL profiling more efficient, serving multiple needs and environmental applications, and finally capitalizing existing science and technology investments in Europe.

Thus, the main research objective of PROBE is to efficiently and cost-effectively reduce the observational gap in ABL profiling at European scale and to extend the field of applications that can benefit from these ABL profiling data.

\section{Challenges}

To answer the main research question, the following four challenges have been identified:

- Challenge 1: Capacity building to enhance knowledge exchange between academia, industry and end-users for exploiting the full potential of ABL profiling for societal benefit;

- Challenge 2: Enhancing pan-European research coordination to develop advanced ABL profiling products and tools for data assimilation and long time series reanalysis;

- Challenge 3: Fostering coordination between operational agencies, academia and industry to tailor measurement networks for clearly identified applications;

- Challenge 4: Capacity building to improve the operation and data quality of existing ABL profiling instruments for integration within a European network.

To address the above challenges, five groups of actors have been identified:

1. Academia: Scientists from Universities and research institutes;

2. Industry: Manufacturers of ABL profiling instruments;

3. Operational agencies: Entities operating individual or networks of ABL instruments in an operational context for societal need (e.g. weather, air quality);

4. Sustained research structures: Networks of ABL instruments operated for research purposes; 
5. End-users: groups whose activity can benefit from the use of ABL measurements in different sectors (e.g. energy, transport, health).

The main goal of PROBE is thus to create a cooperation hub where these groups can communicate their objectives and requirements, share expertise on observations and applications and develop novel strategies to further exploit ABL data with the aim to maximize societal impact.

\section{Objectives}

The overall objective of PROBE is to develop homogenized and traceable methods to costeffectively close the ABL observational gap at European level. These methods will allow for immediate implementation in short-term applications, while also provisioning long-term sustainable research.

The following specific research coordination and capacity building objectives are defined and aligned with the four challenges introduced above:

\section{Challenge 1 (knowledge exchange)}

Objective 1.1: Establish a stakeholder platform for identified user groups across stakeholder types, EU member states, non-EU countries and transnational organizations to collate, review and define ABL profiling user needs.

Objective 1.2: Develop a conceptual framework common to all measurements, including the identification of necessary methods and tools for the entire processing chain from measurement to end-user product (including operations, networking, retrieval, impact evaluation).

Objective 1.3: Capacity building for end-users through training and demonstration on the use and impact of ABL products in multiple applications for societal benefit.

2. Challenge 2 (advanced ABL profiling)

Objective 2.1: Identify ABL parameter needs of different stakeholder groups and EU programmes through dedicated workshops, reports, review and white papers.

Objective 2.2: Develop higher level products from the synergy of co-located ABL profiling instruments, including advanced atmospheric thermodynamic, aerosol and cloud profiling products and their "best estimates". Promote coordination of field experiment efforts planned at national and international levels, including technology/methodology comparison and/or performance assessment, ensuring efficient planning and impact maximization.

Objective 2.3: Build capacity in exploiting advanced ABL profiling data for short-term weather forecasts, aviation hazards, renewable energy applications, pollution dispersion, carbon budget monitoring and long-term climate applications.

3. Challenge 3 (tailor measurement networks)

Objective 3.1: Improve the capabilities of existing ABL instrument networks through (a) the design of harmonized data and metadata formats, near real-time processing, optimal 
measurement strategy building on existing network implementation experience and (b) the promotion of cooperation between academia and agencies to support better integration and use of ABL profilers.

Objective 3.2: Design optimized geographical distributions of ABL instrument networks relevant to high-impact applications that could benefit from more ABL data (e.g. urban environments). Exploit the mutual benefits of reference (less dense, more accurate) and comprehensive (denser, less accurate) networks.

Objective 3.3: Enlarge the network capacity by engaging existing ABL profiling systems in Europe that are not yet integrated within the emerging networks. Enable institutions identified as national point-of-contact to assist national operators in performing observations and acquiring and deploying new instrumentation suitable for inclusion in a European scale network.

4. Challenge 4 (operation and data quality)

Objective 4.1: Improve the quality and maturity of ABL profiling data across heterogeneous networks through (a) better operational procedures and tools, and (b) harmonized data interpretation algorithms and codes suited for network application.

Objective 4.2: Promote innovation in ABL measurements (a) through close cooperation with manufacturers leading to hardware, software and firmware improvements, and (b) by investigating emerging new $\mathrm{ABL}$ profiling technologies and their potential for future network deployment and synergy applications.

Objective 4.3: Develop an agenda targeting operational ABL profiling in Europe, coordinating science and technology development addressing operational aspects and longterm services. Identify and establish centres with sufficient expertise to serve as points-ofcontact for disseminating methods and tools.

\section{Implementation}

The understanding, monitoring and forecasting of ABL features require interdisciplinary knowledge, ranging from fundamental science, technology engineering and operational skills. Thus, in order to address to its objectives, PROBE is built on an interdisciplinary network of experts including university departments (Physics, Atmospheric Sciences, Meteorology), national meteorological and hydrological services (NMHS), national research institutions, operational agencies and private sector (instrument manufacturers, weather-related services).

This network allows PROBE access to many ABL profiling instruments distributed across Europe and several highly instrumented test-bed sites. Sites are located in typical Alpine, Mediterranean, Baltic, Atlantic and continental regions, enabling the investigation of most of the ABL climatology types (marine, coastal, sub-arctic, continental, alpine, urban).

Activities within PROBE are organized through four Working Groups (WG), each addressing one of the four challenges identified above. The mutual interactions of the four WG are pictured in Fig. 1.

In line with previous COST Actions, PROBE will promote non-commercial and open-source software solutions. This is the case for RTTOV-gb (freely distributed through https://www.nwpsaf. eu/site/software/rttov-gb/), raw211 (https:/sourcesup.renater.fr/projects/sirta-raw211/), mwr_pro 


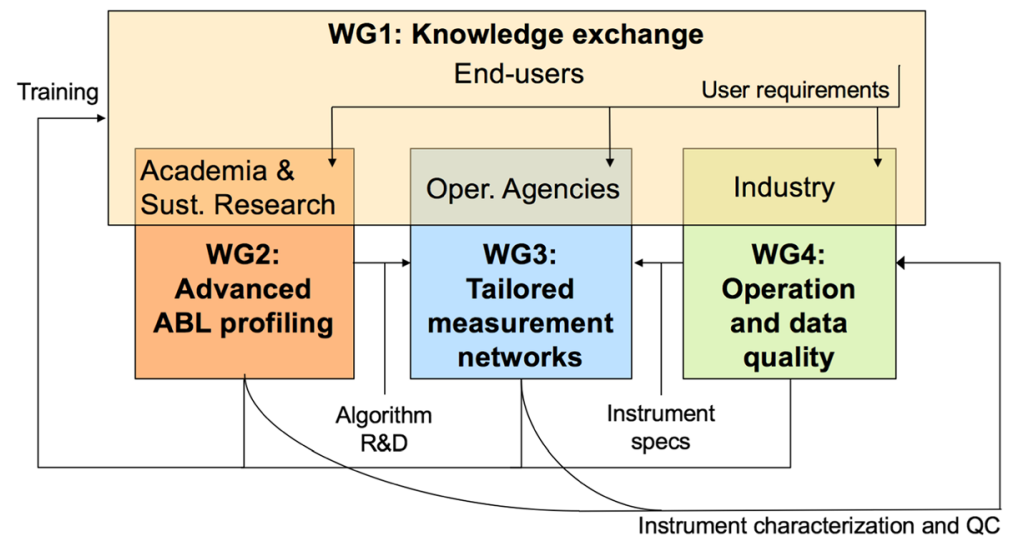

Fig. 1 Working groups (WG) and their interactions within COST Action CA18235 PROBE (R\&D, research and development; QC, quality control).

WG1 (knowledge exchange) aims at coordinating the exchange of ABL profiling knowledge between different groups of stakeholders. WG1 members shall include representatives from all the five identified stakeholder groups. WG1 will interact with all other WGs: with WG2 to exchange needs and specifications for higher level products; with WG3 to define the network observation strategy; with WG4 to optimally define instrument characterization and quality control.

WG2 (advanced ABL profiling) aims at coordinating the development of new and improved ABL products from the synergy of ABL profiling instruments as well as tools for data assimilation and long-term time series. WG2 shall bring together scientists from different European research institutions working on the complementarity of multi-sensor platforms, NWP and/or climate applications. WG2 will address specific topics, such as thermodynamic stability, ABL height, cloud and fog properties, wind and turbulence. WG2 members are mostly remote sensing and ABL scientists. WG2 will interact with WG4 concerning instrument characterization, quality control and retrieval algorithms, and with WG1 to receive user requirements for applications.

WG3 (tailored measurement networks) aims at improving the capabilities of ABL profiling networks by developing harmonized data and metadata formats, common data processing methods and identifying optimal measurement strategies. WG3 shall closely cooperate with E-PROFILE for those instruments that are already included (ALC and RWP) and shall transfer the E-PROFILE approach to other sensors (e.g. MWR, DWL and CR). In WG3, studies towards an optimized instrument setup shall yield how many instruments within a given domain are needed to fulfil the user needs defined in WG1. WG3 members are mostly instrument, communication and data assimilation experts. WG3 will interact with WG4 concerning instrument characterization and quality control, and with WG1 to receive the user requirements for applications.

WG4 (operation and data quality) aims to coordinate the development of tools and methods to support improved instrument operations, and the development of standardized methods for transforming instrument output into physical ABL properties for each considered instrument type. WG4 members are mostly instrument experts and manufacturers. WG4 will interact with WG1, WG2 and WG3 to receive the user requirements for applications, synergy and data assimilation and network coordination, respectively

(ftp://gop.meteo.uni-koeln.de/pub/loehnert/mwr_data_flow/) and other software that will be developed and maintained within PROBE. Any contribution from PROBE must be documented and accessible to users, even when involving manufacturers, as already experienced in previous COST Actions (e.g. firmware update following Kotthaus et al. 2016).

\section{International liaisons}

PROBE will coordinate with existing efforts not only at European level but also at international level. 
At global level, the World Meteorological Organization (WMO) expressed strong support for the objectives of PROBE through the Director of the Research Department. PROBE will establish cooperation with the WMO, particularly the working group on Data Assimilation and Observing Systems (DAOS) and the Commission for Instruments and Methods of Observation (CIMO). PROBE will support DAOS in developing ABL data assimilation tools for improving NWP forecast and also will contribute to the CIMO mission with characterization and standardization of ABL observing systems and methodologies. In return, WMO will upscale PROBE's achievements to the global scale of the WMO Global Observing System.

At European level, the activities carried out within PROBE should be beneficial to the ACTRIS initiative for constructing a long-term research infrastructure (ACTRIS-RI) providing expert services to the community in a sustainable manner for 20 years. In fact, several multiinstrumented stations operated by national research institutes and universities involved in ACTRIS-RI include ABL profiling instruments listed in the "Introduction" section, whose performance will be improved by PROBE activities. The scientific services that ACTRIS-RI will provide to end-users have been defined within the ACTRIS Preparatory Phase Project (ACTRIS-PPP, 2017-2019, in terms of access to data and to expertise for instrument operation, calibration and exploitation. A follow-on project (ACTRIS-IMP) will support this implementation phase from 2020 to 2024. PROBE will identify a series of proposals for high-quality services that may be considered within ACTRIS-IMP towards the long-term implementation in ACTRIS-RI.

PROBE will also be beneficial to the European E-PROFILE programme. In fact, EPROFILE is responsible for developing the wind, cloud and aerosol profiling part of the EUMETNET Composite Observing System. E-PROFILE will produce a series of business cases for future use of RWP, DWL and MWR by the end of 2020. PROBE will serve as an external advisory board for E-PROFILE, ensuring that state-of-the-art procedures and methods are implemented. Leveraging expert and manufacturer networking, PROBE will also develop and test new and improved methods for direct implementation by EPROFILE.

Finally, PROBE will interact with the Integrated Carbon Observation System (ICOS), a pan-European research infrastructure (www.icos-ri.eu) providing harmonized data on the carbon cycle and greenhouse gas budget. ICOS manifested the need for 2-D spatial distributions of the ABL height, which is relevant for the mixing of trace gases in the atmosphere. PROBE will coordinate with ICOS to define user requirements and implement methods to derive ABL height from profiling instrument networks.

Thus, PROBE will establish a multi-fold coordination with the management of existing programs to clarify user requirements for short-term and long-term applications and to demonstrate that quality, reliability and operability of the technologies under consideration meet the scientific and technical requirements.

\section{Innovation potential}

PROBE aims to contribute specific tools and expertise for progressing beyond the state-of-theart in each identified challenge by fostering cooperation and organizing the development of tools and products, such as:

- Improved operation and calibration methods for ABL profiling instruments; 
- Assessment of emerging technologies with regard to future network deployment;

- Tools for monitoring, verification, data assimilation and long-term climate applications using ABL profiling networks;

- New value-added products resulting from synergistic approaches;

- Optimizing network configuration, incorporating the needs of multiple end-users;

- Identification of gaps in existing measurement networks and suggestions for additional measurement locations and settings;

- New application and use of ABL monitoring for improved understanding of ABL processes;

- Demonstration of the relevance of ABL profiling for improved forecast of high-impact severe weather, poor air quality, renewable energy availability, carbon budget monitoring and urban environment specific needs.

In particular, PROBE is expected to contribute to the enhanced understanding of the following research topics.

Air quality The accumulation of pollutants close to the surface is highly dependent on the atmospheric stability and the height of the ABL. ABL profiling instruments considered in PROBE bring relevant information on atmospheric stability, ABL height, vertical winds, turbulence, aerosol content and optical properties. These data may be used to raise air quality alerts in polluted areas such as cities (Chemel et al. 2016) and to evaluate the performance of NWP and chemistry transport forecast models (Martinet et al. 2017), including hazardous pollutants (Calpini et al. 2011). This will advance both scientific understanding and the monitoring and forecasting of air quality and pollution dispersion. Related scientific breakthroughs are expected to have significant socioeconomic impact.

Weather with severe societal consequences A proper characterization of ABL profiles is crucial for the detection of conditions leading to severe weather events. The availability of ABL profiling data on a continental scale will trigger studies (e.g. model verification, data assimilation) to show their added value through experimental demonstration. Tools for NWP data assimilation and model evaluation (e.g. Benedetti et al. 2009; Cimini et al. 2019) will be developed for or adapted to other profiling instruments. These expected high-risk, high-return scientific and technological breakthroughs have the potential to increase societal resilience to severe weather and reduce the associated socioeconomic costs.

Fog monitoring and forecast The potential of ALC to support short-range forecast of fog onset has been demonstrated (Haeffelin et al. 2016). Other instruments considered in PROBE (DWL, MWR, CR) add significant information useful for monitoring and forecasting the complete fog life cycle (formation, duration, dissipation). Considering the impact that fog has on transportation and solar energy sectors, improved short-range fog forecasts would represent a high-value scientific and socioeconomic impact.

Urban meteorology Parameterizations of surface-atmosphere exchanges in NWP and chemical transport models are based on severe simplifications of the complex urban surface. ABL profiling instruments, very suitable for urban deployment where instrumented towers are difficult to build, will help to advance understanding of complex surfaceatmosphere processes. The availability of such measurements is expected to trigger 
development of new research projects to improve parameterization schemes representing boundary layer and urban surface processes that are critical for the advancement of forecast skill in cities (Barlow et al. 2017). More accurate model representations will make the assessment of urban planning strategies related to, e.g., air quality and wind gust formation more realistic. Informing sustainable urban planning with implications for climate change mitigation and resilience to various risk factors is of clear socioeconomic benefit.

Renewable energy Weather strongly impacts the availability of major renewable energy sources (wind, solar, hydro). Climatology and forecast of renewable energy availability impact the energy market from the short to the long range. Accurate and distributed information (wind, aerosol, cloud) at the European scale has the potential to increase the accuracy of climatology and forecast of renewable energy source availability (Gryning et al. 2017; Tuononen et al. 2019). This makes renewable energy more affordable and competitive, with obvious high socioeconomic return.

Aviation meteorology Wind shear and wake turbulence during take-off and landing are among the major dangers in aviation. The detection of dangerous conditions remains challenging. The combination of scanning CR and DWL can provide 3-D wind measurements under all weather conditions (e.g. Thobois et al. 2018). Advanced combined algorithms can be developed to provide turbulence information at high-temporal resolution, which could be provided to pilots and air traffic controllers, with obvious socioeconomic impact. Under certain conditions, aircraft can also induce localized intensification of precipitation during their approach and departure (Moisseev et al. 2019); ALC and DWL are capable of identifying the conditions in which this process is likely to occur and aid airport operations, again providing clear socioeconomic impact.

\section{Early results}

Several stakeholders are already engaging in activities that contribute to the four challenges of the PROBE action. We present 4 highlights of early results already available at the time of the kick-off of the action.

Challenge 1: $\mathrm{ABL}$ products for new stakeholders $\mathrm{ABL}$ dynamics and its resulting vertical structure play an important role for the dispersion of pollutants and greenhouse gases as well as the vertical mixing of heat and moisture. Given its relevance for air quality (Stirnberg et al. 2019) and effects on local climate (e.g. cloud dynamics; Theeuwes et al. 2019), an improved understanding of ABL processes in urban areas is vital for the assessment of planning strategies aiming to mitigate climate change and make cities more resilient to future risk factors. Thanks to recent progress in ALC profiling technology and the development of data processing procedures (Hervo et al. 2016; Kotthaus et al. 2016) and advanced automatic algorithms (Kotthaus et al. 2019), increasingly reliable detection of the ABL structure is now possible. An example of the seasonal diurnal variations in mixed layer height (MLH) observed by ALC in central urban and sub-urban locations in the megacity of Paris (France) is shown in Fig. 2. Consistently higher MLH is found in urban environments $(\sim 100 \mathrm{~m})$. This may be explained by the 


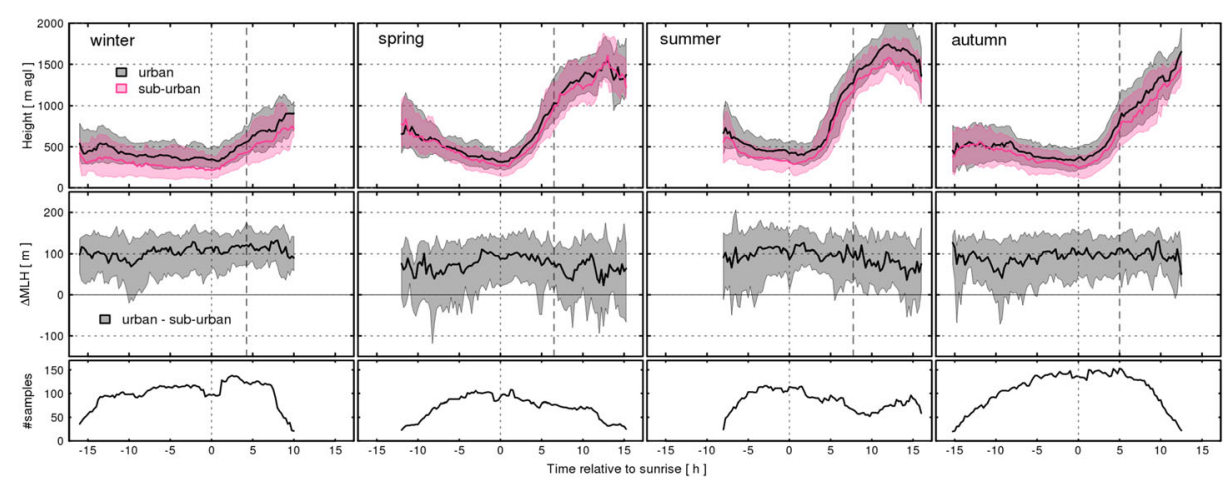

Fig. 2 Seasonal diurnal pattern of mixed layer height (MLH) relative to time since sunrise detected by ALC at a central urban and a sub-urban location in the megacity of Paris, France, during the period December 2016October 2019; (top row) solid line is the median MLH with shading the inter-quartile range, (middle row) median and inter-quartile range of instantaneous differences and (bottom row) number of samples

urban heat island effect, related to anthropogenic heating (especially during winter) and change in surface albedo, further influenced by the occurrence of convective clouds over the urban area (Theeuwes et al. 2019).

Challenge 2: Advanced ABL profiling products PROBE will also help the coordination of advanced ABL profiling through different instrumental synergy techniques and the development of data assimilation tools for new sensors. The Cloudnet algorithms (Illingworth et al. 2007), already applied on large datasets over several European stations, provide vertical profiles of cloud and aerosol properties at a high-temporal resolution though instrumental synergy (mainly CR, lidars and MWR). New instrumental and retrieval techniques now pave the way for advanced synergy by increasing the number of sensors combined together as well, extending retrievals to a larger number of atmospheric variables. The potential added value brought by the synergy of microwave radiometer, cloud radar and ceilometer observations has been demonstrated (e.g. Löhnert et al. 2007; Ebell et al. 2017) on non-drizzling liquid water clouds. A similar approach is currently evaluated at Météo-France to adapt the approach based on optimal estimation approach to combine new $94 \mathrm{GHz}$ CR measurements together with MWR observations and short-term forecasts from the convective scale model AROME (Application of Research to Operations at MEsoscale; Seity et al. 2011), with a focus on fog events. This is possible thanks to the development of forward operators consistent with the AROME model microphysical scheme and vertically pointing $94 \mathrm{GHz}$ cloud radars (Borderies et al. 2018). The direct comparison of simulated radar reflectivity computed from the AROME model with CR observations at the SIRTA observatory has already proved to be valuable to better understand main forecast errors during fog conditions.

Concerning wind profiling, TOPROF demonstrated the capability of long-range DWL for providing information on the sources of turbulent mixing within the atmospheric boundary layer based on the combination of several Doppler lidar-measured quantities (Manninen et al. 2018). The DWL processing chain developed during TOPROF is now being implemented at several DWL sites in Europe within PROBE and has since been extended by the addition of a novel postprocessing algorithm (Vakkari et al. 2019) for improving the instrumental noise floor. This permits the integration of high-temporal resolution data for increasing data availability, and it also improves the accuracy of the retrieved turbulent properties and radial velocity estimates. 
Challenge 3: Demonstrating the added value of regional-scale networks Based on encouraging results on experimental MWR data assimilation into NWP models (Caumont et al. 2016; Martinet et al. 2017), the logical next step is now to go towards the integration of MWR observations into NWP models for data assimilation for high-impact weather events. To that end, an international regional-scale MWR network is currently being deployed in the Southwest of France in the context of the SOuth west FOG 3D (SOFOG3D, https://www.umr-cnrm. fr/spip.php?article1086) experiment for fog processes study led by Météo-France. This MWR network, composed of 8 European units, was deployed thanks to the cooperation within the TOPROF action. PROBE will help promoting the impact brought to NWP forecasts by the assimilation of retrieved profiles at the different sites during fog events using advanced data assimilation techniques. MWR observations are also beneficial to better understand fog processes (Temimi et al. 2019) and evaluate NWP model capabilities.

An attempt to assess the spatial representativeness of ground-based microwave observations and their potential impact in synergy with satellite measurements on retrieval of convective available potential energy (CAPE) has been made. The satellite-based instrument considered in the study is the future Infrared Sounder on board of geostationary Meteosat Third Generation (MTG-IRS). The ground-based instrument is a standard multichannel microwave radiometer.

The COSMO-REA2 reanalysis data (Bollmeyer et al. 2015) was used to simulate groundbased MWR and satellite IRS observations for a $150 \times 150 \mathrm{~km}^{2}$ domain in the west of Germany with 4-km spacing. The MWR observations were simulated using RTTOV-gb (Cimini et al. 2019), the IRS observations using RTTOV. The simulated observations were used to train a neural network retrieval for CAPE for each single instrument as well as for the combination of both. The root-mean-square error (RMSE) of the synergistic retrieval (MWR+ IRS) is $37 \%$ lower than that of IRS only and $13 \%$ lower than MWR only retrieval. Both clearsky and cloudy cases were included.

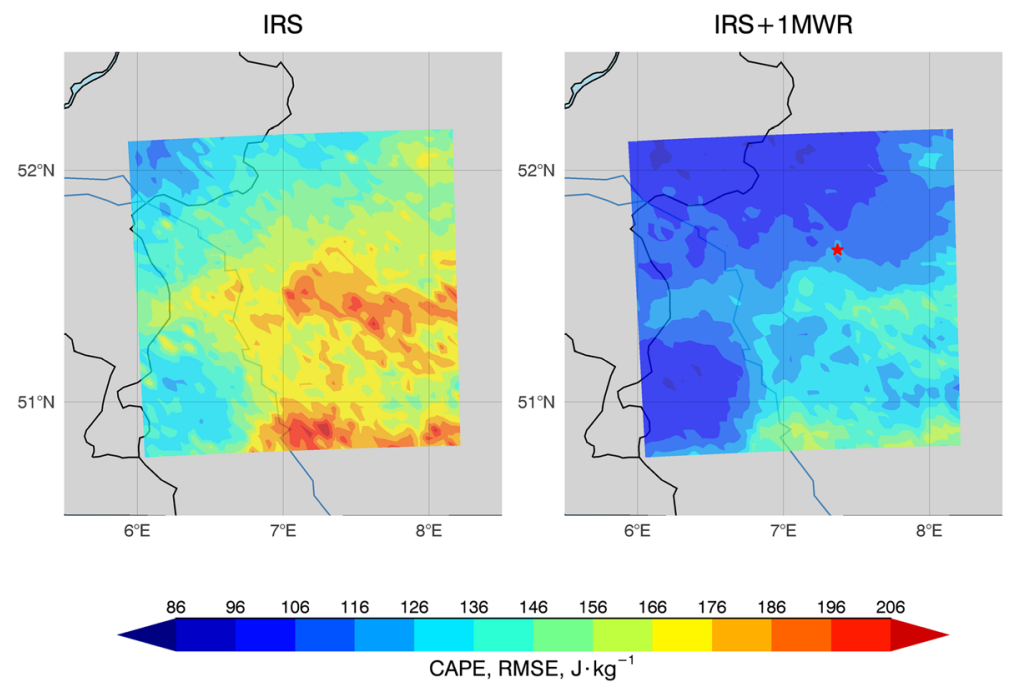

Fig. 3 Left: root-mean-square error of CAPE index calculated from simulated IRS observations over an area in the west of Germany. Right: root-mean-square error of CAPE index calculated from IRS observations including the observations of a single MWR at the grid point marked with red star. Domain size and resolution are $150 \times$ $150 \mathrm{~km}^{2}$ and $4 \mathrm{~km}$, respectively (figure courtesy of Maria Toporov, University of Cologne, Germany) 
Figure 3 (left) shows the regionally specific RMSE of CAPE derived from simulated IRS observations for August 2010. A single MWR is assumed to perform observations at the grid point marked with star (Fig. 3, right). The neural network trained with the synergistic MWR+ IRS observations was applied to the reanalysis profiles at this grid point. The CAPE values at the surrounding grid points, calculated with the IRS only retrieval, were updated by minimizing a cost function based on the uncertainty of the IRS and MWR+IRS retrievals and on spatial correlation of CAPE between grid points. A single ground-based MWR provides valuable improvements and reduces the uncertainty of CAPE domain wide by about $25 \%$ compared with the IRS only retrieval. Further work in the context of PROBE will focus on the estimation of the optimal MWR network configuration and density for retrieval of CAPE and other thermodynamic parameters of the atmosphere.

Challenge 4: Innovative methods to improve data quality One of the outcomes of previous COST Actions (EG-CLIMET and TOPROF) was the demonstration of remote monitoring of MWR data through observation minus background (O-B) statistics (Güldner 2013; Martinet et al. 2015; De Angelis et al. 2017). Such an approach, which compares MWR brightness temperature observations against simulations computed from NWP model outputs with a radiative transfer model (Cimini et al. 2019) is now applied in near real time by Météo-France to a prototype network of three MWR in Europe. It has been demonstrated that the operational O-B statistics, kindly displayed by the Institute of Geophysics and Meteorology of University of Cologne (e.g. http://gop.meteo.uni-koeln.de/ hatpro/dataBrowser/dataBrowser4.html), provide a useful tool for detecting faulty calibration or instrumental drift of remote instruments, as shown in Fig. 4. O-B statistics also provide values for bias correction of the raw measurements consistent with dedicated NWP and radiative transfer models. In a second step, bias-corrected MWR brightness temperatures are processed to infer boundary layer temperature and humidity profiles as well as liquid water path using the Net1D software

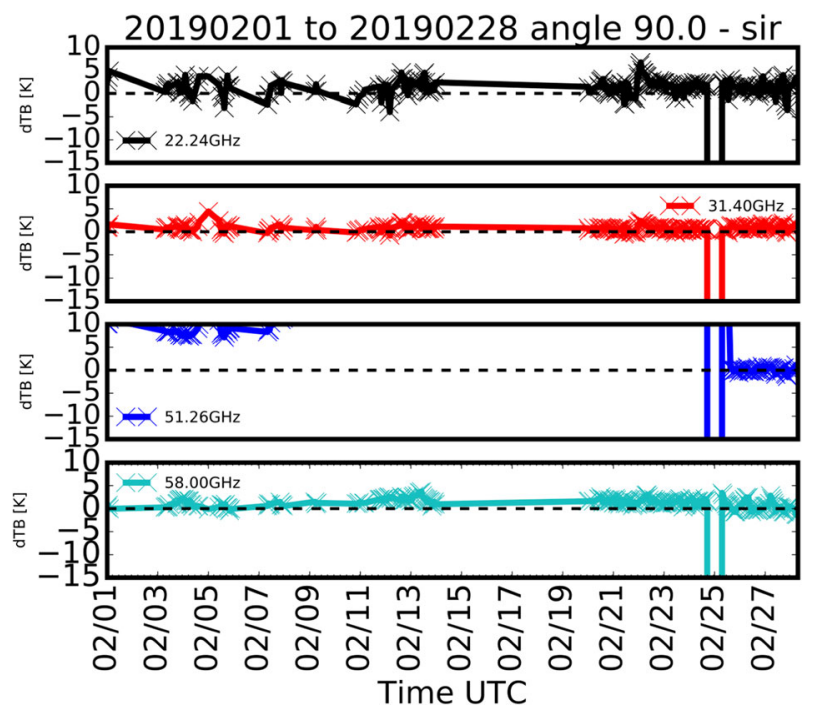

Fig. 4 MWR calibration monitoring through online O-B statistics. Data from the MWR at the SIRTA observatory near Paris $\left(48.80^{\circ} \mathrm{N}, 2.36^{\circ} \mathrm{E}\right)$ during February 2019 are shown. Untypical large bias is detected at $51.26 \mathrm{GHz}$, which is corrected after the recalibration performed on February 25 

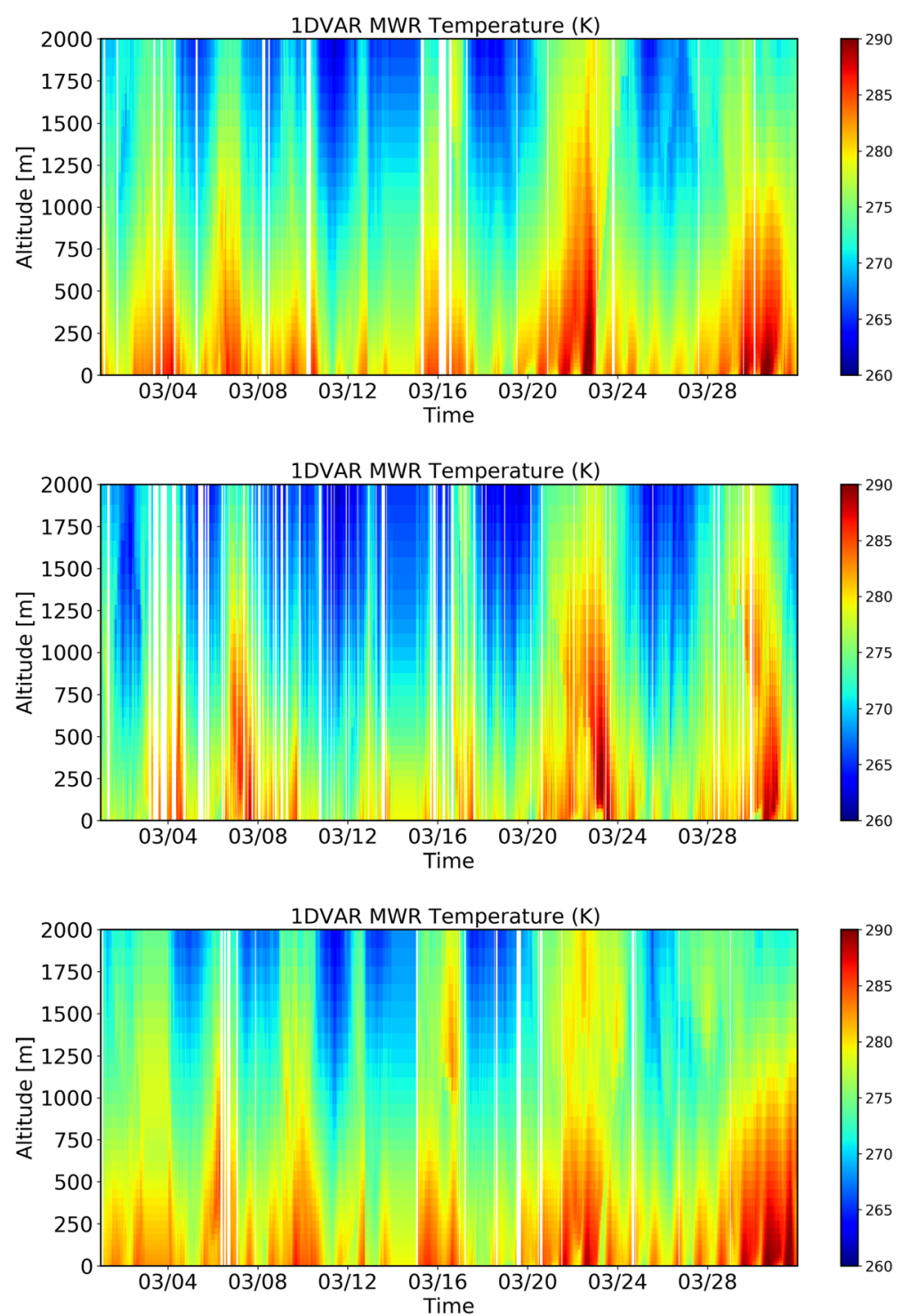

Fig. 5 1-month time series (March 2019) of temperature profiles from MWR operating in three observatories in Europe (top to bottom: Jülich, Germany $\left(50.91^{\circ} \mathrm{N}, 6.41^{\circ} \mathrm{E}\right)$, Lindenberg, Germany $\left(52.21^{\circ} \mathrm{N}, 14.12^{\circ} \mathrm{E}\right)$, SIRTA, France $\left(48.80^{\circ}, \mathrm{N} 2.36^{\circ} \mathrm{E}\right)$. The profile retrievals are obtained consistently throughout the prototype network by processing the MWR brightness temperature observations with the Net1D software developed within the COST action TOPROF

developed within TOPROF for network-consistent one-dimension variational retrievals (Fig. 5). This quasi-operational monitoring has also demonstrated the good stability of MWR measurements as well as the good continuity in the data flow demonstrating the potential of these instruments to be part of future operational networks. This demonstrator will be one component of the E-PROFILE business case for the integration of MWR networks and can be easily extended to other European units. 


\section{Outlook}

The COST Action PROBE (CA18235) started on 29 October 2019. For the next 4 years (20192023), PROBE will pursue its objectives by developing and strengthening the network of researchers, engineers, scholars, industry and other stakeholders in the domain of ABL profiling. This domain requires expertise in different fields (dynamics, thermodynamics, microphysics, engineering), which is distributed among different organizations and countries in Europe. Networking previously poorly connected sectors is crucial for developing new concepts (e.g. instrument synergy), products (best estimate atmospheric retrievals) and services (e.g. data assimilation, useroriented customized forecast). This will be achieved through capacity building of instrument operators to improve the use of state-of-the-art ABL profiling instruments, and by identifying knowledge brokers to enable rapid exchange between academia, operational agencies, industry and end-users to ensure full exploitation for societal benefit. Close cooperation with instrument manufacturers will be fostered to gain mutual benefit: solid instrument characterization for scientists/ users and pathways for improving market-competitive hardware/firmware for manufacturers. This will intensify the links between scientific community, industry, policy makers and society.

PROBE will enhance pan-European research coordination to develop new products and tools for short- and long-term applications. PROBE has the capability to exploit the research and technology outcomes directly in the operational services through the cooperation with European programmes such E-PROFILE, ACTRIS and ICOS, thus ensuring high return for the investments. Finally, PROBE will also facilitate the international collaboration of the European network with other world leaders on ABL profiling, providing the natural platform where cutting-edge science and technology developments are shared, increasing the visibility and impact of European research at a global level.

Acknowledgements This article is based upon preparatory work for COST Action CA18235 "PROBE" supported by COST - European Cooperation in Science and Technology (www.cost.eu). Maria Toporov (from University of Cologne and supported through Research Grant 2015EMF-09, Extramurale Forschung, German Weather Service DWD) is acknowledged for producing Figure 3.

\section{Compliance with ethical standards}

Conflict of interest The authors declare that they have no conflict of interest.

Open Access This article is licensed under a Creative Commons Attribution 4.0 International License, which permits use, sharing, adaptation, distribution and reproduction in any medium or format, as long as you give appropriate credit to the original author(s) and the source, provide a link to the Creative Commons licence, and indicate if changes were made. The images or other third party material in this article are included in the article's Creative Commons licence, unless indicated otherwise in a credit line to the material. If material is not included in the article's Creative Commons licence and your intended use is not permitted by statutory regulation or exceeds the permitted use, you will need to obtain permission directly from the copyright holder. To view a copy of this licence, visit http://creativecommons.org/licenses/by/4.0/.

\section{References}

Barlow JF (2014) Progress in observing and modelling the urban boundary layer. Urban Clim. https://doi. org/10.1016/j.uclim.2014.03.011

Barlow JF et al (2017) Developing a research strategy to better understand, observe and simulate urban atmospheric processes at kilometre to sub-kilometre scales. Bull Amer Meteor Soc. https://doi.org/10.1175 /BAMS-D-17-0106.1 
Benedetti A et al (2009) Aerosol analysis and forecast in the European Centre for Medium- Range Weather Forecasts Integrated Forecast System: 2. Data assimilation. J Geophys Res 114:D13205. https://doi. org/10.1029/2008JD011115

Bollmeyer C, Keller J, Ohlwein C, Bentzien S, Crewell S, Friedrichs P, Hense A, Keune J, Kneifel S, Pscheidt I, Redl S, Steinke S (2015) Towards a high-resolution regional reanalysis for the European CORDEX domain. Q J R Meteorol Soc 141(86):1-15. https://doi.org/10.1002/qj.2486

Borderies M, Caumont O, Augros C, Bresson É, Delanoë J, Ducrocq V, Fourrié N, Bastard TL, Nuret M (2018) Simulation of W-band radar reflectivity for model validation and data assimilation. Q.J.R. Meteorol Soc 144: 391-403. https://doi.org/10.1002/qj.3210

Calpini B, Ruffieux D, Bettems J-M, Hug C, Huguenin P, Isaak H-P, Kaufmann P, Maier O, Steiner P (2011) Ground-based remote sensing profiling and numerical weather prediction model to manage nuclear power plants meteorological surveillance in Switzerland. Atmos Meas Tech 4:1617-1625. https://doi.org/10.5194 /amt-4-1617-2011

Caumont O, Cimini D, Löhnert U, Alados-Arboledas L, Bleisch R, Buffa F, Ferrario ME, Haefele A, Huet T, Madonna F, Pace G (2016) Assimilation of humidity and temperature observations retrieved from groundbased microwave radiometers into a convective-scale NWP model. Q.J.R. Meteorol Soc 142:2692-2704. https://doi.org/10.1002/qj.2860

Chemel C, Arduini G, Staquet C, Largeron Y, Legain D, Tzanos D, Paci A (2016) Valley heat deficit as a bulk measure of wintertime particulate air pollution in the Arve River Valley. Atmos Environ. https://doi. org/10.1016/j.atmosenv.2015.12.058

Cimini D, Rizi V, Di Girolamo P, Marzano FS, Macke A, Pappalardo G, Richter A (2014) Overview: tropospheric profiling: state of the art and future challenges - introduction to the AMT special issue. Atmos Meas Tech 7:2981-2986. https://doi.org/10.5194/amt-7-2981-2014

Cimini D, Hocking J, De Angelis F, Cersosimo A, Di Paola F, Gallucci D, Gentile S, Geraldi E, Larosa S, Nilo S, Romano F, Ricciardelli E, Ripepi E, Viggiano M, Luini L, Riva C, Marzano FS, Martinet P, Song YY, Ahn MH, Rosenkranz PW (2019) RTTOV-gb v1.0 - updates on sensors, absorption models, uncertainty, and availability. Geosci Model Dev 12:1833-1845. https://doi.org/10.5194/gmd-12-1833-2019

Dang R, Yang Y, Hu X-M, Wang Z, Zhang S (2019) A review of techniques for diagnosing the atmospheric boundary layer height (ABLH) using Aerosol Lidar Data. Remote Sens 11:1590. https://doi.org/10.3390 /rs11131590

De Angelis F, Cimini D, Löhnert U, Caumont O, Haefele A, Pospichal B, Martinet P, Navas-Guzmán F, KleinBaltink H, Dupont J-C, Hocking J (2017) Long-term observations minus background monitoring of groundbased brightness temperatures from a microwave radiometer network. Atmos Meas Tech 10:3947-3961. https://doi.org/10.5194/amt-10-3947-2017

Ebell K, Löhnert U, Päschke E, Orlandi E, Schween JH, Crewell S (2017) A 1-D variational retrieval of temperature, humidity, and liquid cloud properties: performance under idealized and real conditions. J Geophys Res Atmos 122:1746-1766. https://doi.org/10.1002/2016JD025945

Emeis S, Schäfer K, Münkel C (2008) Surface-based remote sensing of the mixing-layer height - a review. Meteorol Z. https://doi.org/10.1127/0941-2948/2008/0312

Engelbart D, Monna W, Nash J (2009) Integrated Ground-Based Remote-Sensing Stations for Atmospheric Profiling, COST Action 720 Final Report, EUR 24172. https://doi.org/10.2831/10752

Eyre J, Reid R (2014) Cost-benefit studies of observing systems. In: Forecasting ResearchTechnical Report No: 593, Met Office, 1-11, 2014

Fisher B, Joffre S, Kukkonen J, Piringer M, Rotach M, Schatzmann M (2005) Meteorology applied to Urban Air Pollution Problems, Final Report COST Action 715, ISBN 954-9526-30-5, Online: https:/www.dmu. $\mathrm{dk} /$ atmosphericenvironment/cost/docs/Cost715-final.pdf Accessed 05 November 2019

Friehe CA (1987) Review of atmospheric boundary layer research, 1983-1986. Rev Geophys 25(3):387-392. https://doi.org/10.1029/RG025i003p00387

Garratt JR (1994) Review: the atmospheric boundary layer. Earth-Sci Rev 37(1-2):89-134 ISSN 0012-8252. https://doi.org/10.1016/0012-8252(94)90026-4

Gryning SE, Mikkelsen T, Baehr C, Dabas A, Gómez P, O’Connor E, Rottner L, Sjöholm M, Suomi I, Vasiljević N (2017) Measurement methodologies for wind energy based on ground-level remote sensing. https://doi. org/10.1016/B978-0-08-100504-0.00002-0

Güldner J (2013) A model-based approach to adjust microwave observations for operational applications: results of a campaign at Munich Airport in winter 2011/2012. Atmos Meas Tech 6:2879-2891. https://doi. org/10.5194/amt-6-2879-2013

Haeffelin M, Angelini F, Morille Y, Martucci G, Frey S, Gobbi GP, Lolli S, O’Dowd CD, Sauvage L, XuerefRémy I, Wastine B, Feist DG (2012) Evaluation of mixing-height retrievals from automatic profiling Lidars and ceilometers in view of future integrated networks in Europe. Boundary-Layer Meteorol 143:49-75. https://doi.org/10.1007/s10546-011-9643-z 
Haeffelin M, Laffineur Q, Bravo-Aranda J-A, Drouin M-A, Casquero-Vera J-A, Dupont J-C, De Backer H (2016) Radiation fog formation alerts using attenuated backscatter power from automatic Lidars and ceilometers. Atmos Meas Tech 9:5347-5365. https://doi.org/10.5194/amt-9-5347-2016

Hardesty RM, Hoff RM, Hoff RM, Hardesty RM, Carr F, Weckwerth T, Koch S, Benedetti A, Crewell S, Cimini D, Turner D, Feltz W, Demoz B, Wulfmeyer V, Sisterson D, Ackerman T, Fabry F, Knupp K (2012) Thermodynamic Profiling Technologies Workshop report to the National Science Foundation and the National Weather Service. NCAR Technical Note 488, NCAR/TN-488+STR, ISSN:2153-2397. https://doi.org/10.5065/D6SQ8XCF

Hervo M, Poltera Y, Haefele A (2016) An empirical method to correct for temperature dependent variations in the overlap function of CHM15k ceilometers. Atmos Meas Tech Discuss 1-27. https://doi.org/10.5194/amt2016-30

Illingworth AJ, Hogan RJ, O’Connor E, Bouniol D, Brooks ME, Delanoé J, Donovan DP, Eastment JD, Gaussiat N, Goddard JW, Haeffelin M, Baltink HK, Krasnov OA, Pelon J, Piriou J, Protat A, Russchenberg HW, Seifert A, Tompkins AM, van Zadelhoff G, Vinit F, Willén U, Wilson DR, Wrench CL (2007) Cloudnet Bull Amer Meteor Soc 88:883-898. https://doi.org/10.1175/BAMS-88-6-883

Illingworth AJ, Ruffieux D, Cimini D, Löhnert U, Haeffelin M, Lehmann V (2013) COST Action ES0702 EGCLIMET - Final Report. https://doi.org/10.12898/ES0702FR

Illingworth A, Cimini D, Gaffard C, Haeffelin M, Lehmann V, Loehnert U, O'Connor E, Ruffieux D (2015) Exploiting existing ground-based remote sensing networks to improve high resolution weather forecasts, bull. Amer Meteor Soc. https://doi.org/10.1175/BAMS-D-13-00283.1,February

Illingworth A, Cimini D, Haefele A, Haeffelin M, Hervo M, Kotthaus S, Loehnert U, Martinet P, Mattis I, O'Connor E (2019) How can existing ground-based profiling instruments improve European weather forecasts? Bull Amer Meteor Soc. https://doi.org/10.1175/BAMS-D-17-0231.1, 606-619 April

Kotthaus S, O’Connor E, Münkel C, Charlton-Perez C, Haeffelin M, Gabey AM, Grimmond CSB (2016) Recommendations for processing atmospheric attenuated backscatter profiles from Vaisala CL31 ceilometers. Atmos Meas Tech 9:3769-3791. https://doi.org/10.5194/amt-9-3769-2016

Kotthaus, S., Haeffelin, M., Drouin, M.-A., Dupont, J.-C., Grimmond, C., Haefele, A., Hervo, M., Poltera, Y., Wiegner, M., 2019. Taking advantage of common automatic Lidar and ceilometer (ALC) systems: tailored algorithms for the detection of the atmospheric boundary layer structure, in prep.

Löhnert U, van Meijgaard E, Baltink HK, Groß S, Boers R (2007) Accuracy assessment of an integrated profiling technique for operationally deriving profiles of temperature, humidity, and cloud liquid water. J Geophys Res 112:D04205. https://doi.org/10.1029/2006JD007379

Manninen, A. J., T. Marke, M. J. Tuononen and E. J. O’Connor ( 2018). Atmospheric boundary layer classification with Doppler Lidar. J Geophys Res Atmos, 123, 8172-8189, https://doi.org/10.1029/2017 JD028169

Martinet P, Dabas A, Donier JM, Douffet T, Garrouste O, Guillot R (2015) 1D-Var temperature retrievals from microwave radiometer and convective scale model. Tellus A 67:27925. https://doi.org/10.3402/tellusa. v67.27925

Martinet P, Cimini D, De Angelis F, Canut G, Unger V, Guillot R, Tzanos D, Paci A (2017) Combining groundbased microwave radiometer and the AROME convective scale model through 1DVAR retrievals in complex terrain: an Alpine valley case study. Atmos Meas Tech 10:3385-3402. https://doi.org/10.5194 /amt-10-3385-2017

Mätzler C(ed.) (2000) Radiative transfer models for microwave radiometry, application of microwave radiometry to atmospheric research and monitoring, COST Action 712, Final Report Project 1, European Commission, Directorate General for Research, EUR 19543, ISBN 92-828-9842-3

Moisseev D, Lautaportti S, Alku L, Tabakova K, O’Connor EJ, Leskinen M, Kulmala M (2019) Inadvertent localized intensification of precipitation by aircraft. J Geophys Res Atmos 124:2094-2104. https://oi. org/10.1029/2018JD029449

Nash J, Monna W, Dibbern, J (2003) Development of VHF/UHF wind profilers and vertical sounders for use in European observing systems, COST Action 76 final report, ISBN 92-894-4899-7, ISSN 1018-5593

National Research Council (2009) Observing weather and climate from the ground up: a nationwide network of networks, ISBN: 978-0309-12986-2

National Research Council (2010) When weather matters: science and service to meet critical societal needs, ISBN: 978-0-309-15249-5

Seibert P, Beyrich F, Gryning SE, Joffre S, Rasmussen A, Tercier P (2000) Review and intercomparison of operational methods for the determination of the mixing height. Atmos Environ 34(7):1001-1027

Seity Y, Brousseau P, Malardel S, Hello G, Bénard P, Bouttier F, Lac C, Masson V (2011) The AROME-France convective- scale operational model. Mon Weather Rev 139:976-991

Stirnberg, R., Cermak, J., Kotthaus, S., Haeffelin, M., Fuchs, J., Andersen, H., Kim, M., 2019. Variability of air pollution (PM1) analysed using explainable Machine Learning, in prep. 
Stull RB (1988) An introduction to boundary layer meteorology. Kluwer Academic Publishers, Dordrecht/ Boston/London, ISBN 9027727686

Temimi M, Morais Fonseca R, Reddy Nelli N, Valappil VK, Weston MJ, Thota MS, Wehbe Y, Yousef L (2019) On the analysis of ground-based microwave radiometer data during fog conditions. Atmos Res. https:/doi. org/10.1016/j.atmosres.2019.104652

Theeuwes, N.E., Barlow, J.F., Teuling, A.J., Grimmond, C.S.B., Kotthaus, S., 2019. Persistent cloud cover over mega-cities linked to surface heat release. npj Clim. Atmos Sci 2, 1-15. doi:https://doi.org/10.1038/s41612019-0072-x

Thobois L, Cariou JP, Gultepe I (2018) Review of Lidar-based applications for aviation weather. Pure Appl Geophys 176:1959-1976. https://doi.org/10.1007/s00024-018-2058-8

Thorne PW, Madonna F, Schulz J, Oakley T, Ingleby B, Rosoldi M, Tramutola E, Arola A, Buschmann M, Mikalsen AC, Davy R, Voces C, Kreher K, De Maziere M, Pappalardo G (2017) Making better sense of the mosaic of environmental measurement networks: a system-of-systems approach and quantitative assessment. Geosci Instrum Method Data Syst 6:453-472. https://doi.org/10.5194/gi-6-453-2017

Tuononen M, O'Connor EJ, Sinclair VA (2019) Evaluating solar radiation forecast uncertainty. Atmos Chem Phys 19:1985-2000. https://doi.org/10.5194/acp-19-1985-2019

Vakkari V, Manninen AJ, O’Connor EJ, Schween JH, van Zyl PG, Marinou E (2019) A novel post-processing algorithm for Halo Doppler lidars. Atmos Meas Tech 12:839-852. https://doi.org/10.5194/amt-12-839-2019

\section{Affiliations}

\section{Domenico Cimini $^{1,2} \cdot$ Martial Haeffelin $^{3} \cdot$ Simone Kotthaus $^{3} \cdot$ Ulrich Löhnert $^{4} \cdot$ Pauline $^{2}$ Martinet $^{5} \cdot$ Ewan $\mathrm{O}^{\prime}$ Connor $^{6} \cdot$ Christopher Walden $^{7} \cdot$ Martine Collaud Coen $^{8} \cdot$ Jana Preissler ${ }^{9,10}$}

1 National Research Council of Italy, Institute of Methodologies for Environmental Analysis (CNR-IMAA), Potenza, Italy

2 Center of Excellence CETEMPS, University of L'Aquila, L'Aquila, Italy

3 Institut Pierre-Simon Laplace (IPSL), CNRS, Ecole Polytechnique, Palaiseau Cedex, France

4 Institute for Geophysics and Meteorology, University of Cologne, Cologne, Germany

5 CNRM UMR 3589, Meteo-France/CNRS, Toulouse, France

6 Finnish Meteorological Institute, Helsinki, Finland

7 UK Research and Innovation and National Centre for Atmospheric Science (NCAS), Chilbolton Observatory, Drove Rd, Chilbolton, Stockbridge SO20 6BJ, UK

8 Federal Office of Meteorology and Climatology MeteoSwiss, Payerne, Switzerland

9 National University of Ireland Galway, Galway, Ireland

10 Present address: Leosphere, Saclay, France 